International Journal of Engineering \& Technology, $7(2.24)(2018) 545-551$
International Journal of Engineering \& Technology
SPC
Website: www.sciencepubco.com/index.php/IJET
Research paper

\title{
Adaptive filter based current controller for Shunt Active filter
}

\author{
R. Sriranjani*, S. Jayalalitha \\ EEED, SEEE, SASTRA,Tirumalaisamudram \\ *Corresponding Author Email: mathusri@eee.sastra.edu.
}

\begin{abstract}
This paper deals with the harmonic mitigation and reactive power compensation using Shunt Active filter. The performance of the Shunt active filter depends on the design and current control technique for generating a reference current. The design of the filter involves the iterative procedure for choosing the filter components so that it compensates the harmonics and reactive power for maximum load condition. The current controller method adopted for indirect current control technique where the reference signal is similar to the supply current signal. The Adaptive filter used in current controller mitigates harmonics and reactive power and voltage control loop of SAF balancing the active power between the load and supply unit. The learning rate is fixed by repeated simulation. The SAF active filter is tested in four load condition ie., nonlinear load(37\% Total Harmonic Distortion(THD)), highly nonlinear load(>100\% THD), linear load(<8\% THD, power factor(pf) <0.5) and both nonlinear and linear load(37\% THD and 0.7 pf). The study is carried out in MATLAB Simulink and the results are presented.
\end{abstract}

Keywords- Harmonics; nonlinear load; current controller; Shunt Active Filter.

\section{Introduction}

Harmonics and reactive power alleviation are the crucial power quality issue because of the usage of power electronics devices in industrial and domestic applications. Many filters are designed to infuse the harmonics and reactive current to the supply mains. The Active filter compensates the harmonics and static VAr compensates the reactive power [1-6], but both compensation is still under research. The lessening of both issues depends upon the reference current generated by the control algorithm and current controller of the Shunt Active filter (SAF). The control algorithms extort the fundamental component of the load current or the harmonic component of the load current. The elemental algorithm is synchronous reference frame and pq algorithm, the former gives promising results only for the balanced sinusoidal voltage condition and later one gives effective results for any condition. Both involved many transformations and mathematical calculation. Many types of reference current generator of APF are proposed in the literature [1-5]. The harmonic current can be extracted from the load current using frequency domain and time domain. The frequency domain techniques primarily depend on the use of the Fast Fourier Transform, Discrete Fourier Transform, Wavelet analysis [4,7]; offers an exact reference current in steady-state condition, but execution in real-time, requires more computational effort, as a result, a long time delay is introduced in the system response. This increases the researchers to focus on time domain-based techniques. The commonly used time domain technique is the pq theory, i.e. measuring the instantaneous active and reactive power [8,9] and the Synchronous Reference Frame (SRF) alternatively called dq methods [10]. The two algorithms offer a better response than frequency domain control algorithm, guaranteed compensation under all operating conditions. The instantaneous pq theory which is known as a feasible elucidation to the contamination produced by solid state based electrical load and is commonly employed [11]. The paper suggests a direct current control technique and acquiring a power which is the difference between $p$ and q.

An adaptive filter is a self-amending digital filter that alters its coefficients to lessen the error signal so that the system characteristics match with the desired outcome [12,19-21]. There are different types of filter configurations such as system identification, noise cancellation, linear prediction and Inverse systems. The adaptive algorithms update the weights using Least Mean Square (LMS) Algorithm, Normalized LMS algorithm or Recursive Least Square (RLS) algorithm [13, 14]. The noise cancellation system [15] has the reference signal and primary signal and it differs from other types because of the two input signal given to the system is shown in fig 1 . The noise signal estimated from the primary signal consists of the actual signal with noise and it is subtracted from the signal generated from the adaptive filter.

Input signal

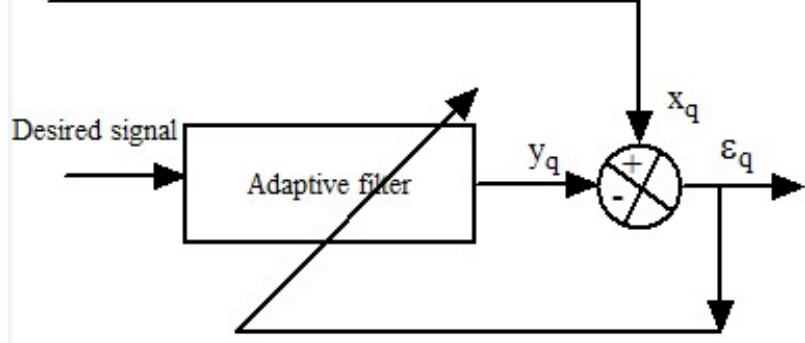

Fig. 1: Noise cancellation system

In this paper, the harmonic compensation and reactive power compensation for the different loads are taken for the study to prove the reactive power compensation and harmonic compensation. 


\section{System Configuration}

A three phase three wire SAF connected with the three phase diode bridge rectifier load and three phase linear load shown in fig 2. Proper tuning of $\mathrm{Lf}$ and $\mathrm{Cdc}$ of SAF provides smooth filter current and Vdc of SAF. Cdc is chosen in such a way that it eliminates high frequency signal in the waveform. Nonlinear load effect is increased to study the harmonic effect and the performance of the proposed algorithm is observed and linear load effectiveness is increased to study the proposed algorithm under this situation.

Synchronous reference frame(traditional) and least mean square (proposed) algorithm are implemented in the system configuration and the results are analyzed.

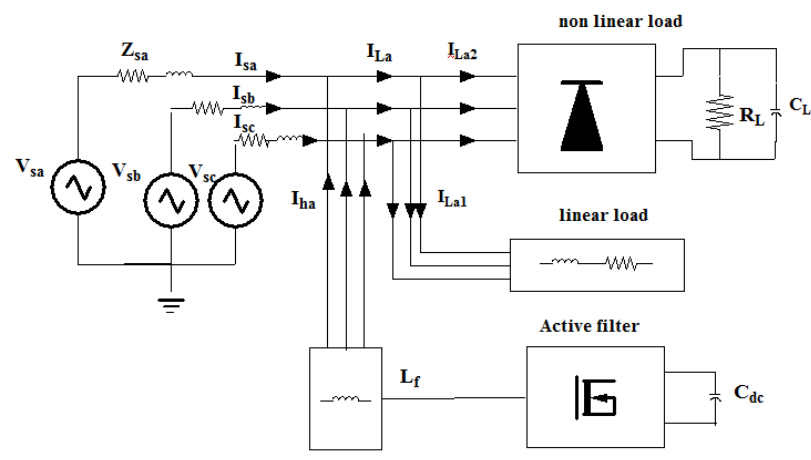

Fig. 2: System configuration

\section{Adaptive Filter Using LMS Algorithm}

The tap-weight vector computed for each iteration in the adaptive filter by using the method of steepest-descent with a suitable value of gradient vector $(\nabla)$ and step size $(\mu)$ would indeed converge to the optimum value. [16].

The disadvantage with fixed value of " $\mu$ " is that the LMS algorithm is not able to achieve minimum static error with fast convergence rate [17]. When , $\mu^{\mu e}$ is high, the convergence is fast with increased static error. However, when „, $\mu^{\text {ee }}$ is small, convergence is slow with reduced static error.

This filtering approach provides fast and accurate estimation of sinusoidal fundamental current from distorted load currents by minimizing the error between sensed and estimated currents. The LMS technique along with its variants has been used in several power system studies including the shunt compensation. Several advantages offered by LMS algorithm by means of simplicity and computational efficiency make it perfect choice for constant load compared to other proposed algorithms.

The fundamental current extraction using adaptive filter is given by the following equation

The error signal is given by,

$$
\begin{aligned}
& \varepsilon_{q}=d_{q}-y_{q} \\
& y_{q}=\nabla_{q}^{T} X_{q}
\end{aligned}
$$

where $\mathrm{dq}$ is the primary signal, $\mathrm{X}_{\mathrm{q}}$ is the reference signal to a digital filter, $\mathrm{y}_{\mathrm{q}}$ is the output signal

The Least square algorithm fine tune the coefficients of the digital filter and the weight is updated by

$$
\begin{aligned}
& \nabla_{q+1}^{\prime}=\nabla_{q}+2 \mu \varepsilon_{q} X_{q} \\
& \nabla_{q}
\end{aligned}
$$

$\varepsilon_{\mathrm{q}}$ is the error signal of yq and dq.

The adaptive filter noise cancellation is a suitable algorithm to obtain the fundamental component from the harmonic $\mathrm{I}_{\mathrm{L}}$.
The load current is highly distorted and lags the supply voltage and is given by,

$$
\begin{gathered}
I_{L 1 a}(t)=\sum_{h=1}^{\infty} I_{m a h} \sin \left(h \omega t-q_{h}\right) \\
\begin{aligned}
I_{L 1 a}(t)= & I_{1 a} \sin \left(\omega_{1} t-q_{1}\right)+ \\
& \sum_{h=2}^{\infty} I_{m a h} \sin \left(h \omega_{1} t-q_{h}\right) \\
I_{L 1 a}(t)= & I_{1 a} \sin \omega t \cos q_{1}-I_{a 1} \cos \omega t \sin q_{1} \\
& +\sum_{h=2}^{\infty} I_{\text {mah }} \sin \left(h \omega_{1} t-q_{h}\right) \\
I_{L 1 a}(t)= & I_{f 1 a}(t)+I_{\text {reat } 1 a}(t)+I_{\text {har } 1 a}(t)
\end{aligned}
\end{gathered}
$$

The load current is considered as a primary signal extract the fundamental active component which is the output signal ( $\left.\mathrm{I}_{\mathrm{fla}}\right)$.

$$
\begin{aligned}
& I_{f 1 a}(t)=I_{1 a}^{\prime} \sin \omega t \\
& \text { Where } I_{1 a}^{\prime}=I_{1 a} \cos q_{1} \\
& \sin \omega t=\frac{I_{f 1 a}(t)}{I_{1 a}^{\prime}}
\end{aligned}
$$

The sine wave is generated from the supply voltage and is taken as the reference signal for the digital filter

$$
\begin{aligned}
V_{s}(t) & =V_{m a} \sin \omega t \\
V_{s}(t) & =V_{m a} \frac{I_{f 1 a}}{I_{1 a}^{\prime}} \\
I_{f 1 a} & =V_{s}(t) \frac{I_{1 a}^{\prime}}{V_{m a}} \\
I_{f 1 a} & =V_{s}(t) \times w_{q} \\
\nabla_{q}= & \frac{I_{1 a}^{\prime}}{V_{m a}}=\frac{I_{1 a}^{\prime} \sin \omega t}{V_{m a} \sin \omega t} \\
= & \frac{I_{f 1 a}(t)}{V_{s}(t)}=\frac{y_{q}}{X_{q}}
\end{aligned}
$$

$\nabla_{\mathrm{q}}$ is the weight of the adaptive filter, $\mathrm{I}_{\mathrm{fla}}(\mathrm{t})$ is the output signal, $\mathrm{V}_{\mathrm{s}}(\mathrm{t})$ is the reference signal of the adaptive filter, $\mathrm{I}_{\mathrm{Lla}}(\mathrm{t})$ is the primary signal of the adaptive filter.

Therefore, the error in equation(1) is compared with equation(7) and is given by and also weight is updated by equation(3)

$$
\begin{gathered}
\varepsilon_{q}=I_{L a}(t)-I_{f 1 a}(t)=I_{\text {reat } 1 a}+I_{h a r 1 a} \\
\nabla_{q+1}=\nabla_{q}+2 \eta\left(I_{s 1 a}(t)-I_{f 1 a}(t)\right) N_{s}(t)
\end{gathered}
$$

The initial value of $\nabla_{\mathrm{q}}(0)$ is taken as $\nabla_{\mathrm{q}}(0)=0$.

The extracted reference current is given by,

$$
I_{r a}(t)=I_{f 1 a}(t)=I_{m 1 a} \sin \omega t
$$


The fundamental current is adjusted by PI controller for power balancing which is given by[18],

$$
\begin{aligned}
& I_{r e f a}(t)=I_{r a}(t)(K+1) \\
& K=\left(v_{d c, r e f}-v_{d c, a c t}\right) K_{p}+ \\
& \left(v_{d c, r e f}-v_{d c, a c t}\right) \frac{K_{i}}{s}
\end{aligned}
$$

\section{Simulation Circuit of Adaptive Filter Using LMS Algorithm}

The adaptive filter is designed using MATLAB simulink blocks and the power circuit is designed using Power system block sets. The supply voltage is $240 \mathrm{~V}, 50 \mathrm{~Hz}$, Rs and Ls are $0.86 \Omega$ and $0.01 \mu \mathrm{H}$, switching frequency $11 \mathrm{kHZ}$, nonlinear load $30 \mathrm{~kW}$, linear load $10 \mathrm{~kW}, \mathrm{~L}_{\mathrm{f}} 300 \mu \mathrm{H}, \mathrm{C}_{\mathrm{dc}} 3000 \mu \mathrm{F}$ and $\mathrm{V}_{\mathrm{dc}, \text { ref }} 800 \mathrm{~V}$. Fig 3. Shows that the simulation circuit of the Adaptive filter using LMS algorithm.ates the balanced three phase reference current only after $100 \mathrm{~ms}$

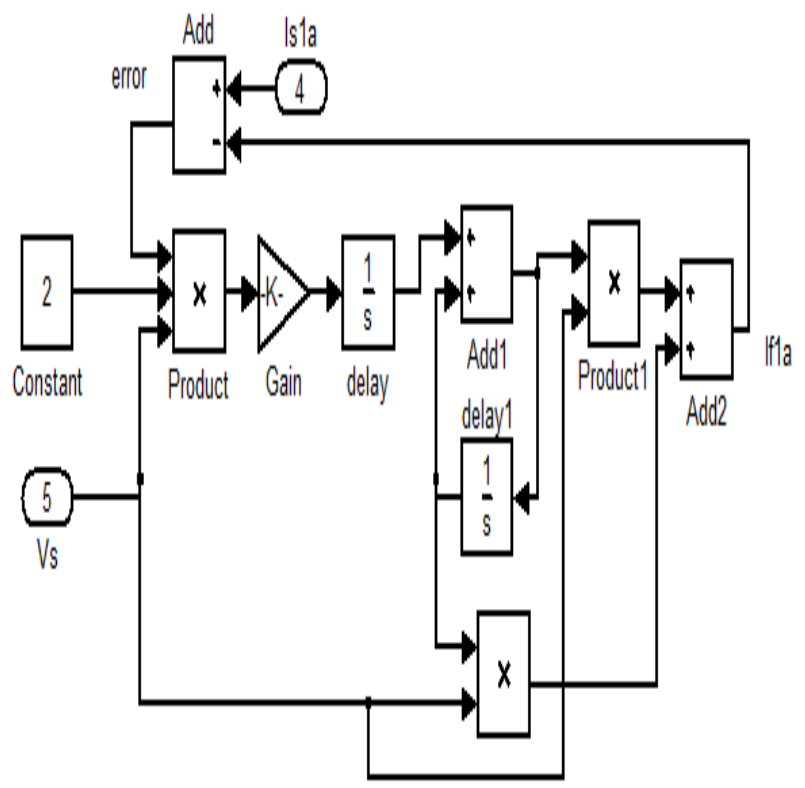

Fig. 3: Simulation circuit of Adaptive Filter using LMS algorithm

\section{Simulation Results of Adaptive Filter for Various}

Types of Load

\section{A. Simulation results for Rectifier Load}

The load current is distorted due to the nonlinear load connected to the supply mains. The waveforms of voltage and current for the rectifier load are shown in Fig 4. the Shunt active filter injects the harmonic current and the supply current is near to sinusoid. Fig 5.shows that the performance of the control algorithm isobserved from the dc bus voltage graph. The FFT spectrum of the load current shows that the THD is $28.7 \%$ and the filter injects the 5th, 7th, 11th and 13th order harmonics respectively. Thus the supply current FFT spectrum shows the reduction in \% THD of 2.21 demonstrated in Fig 6.
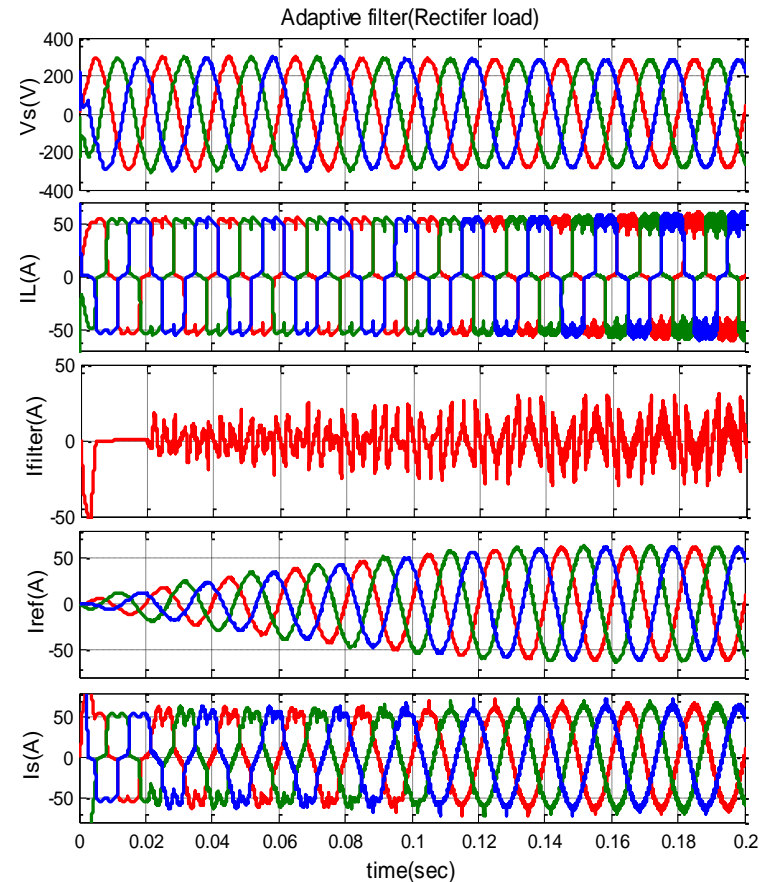

Fig. 4: Supply voltage, load current, filter current, reference current and supply current of Rectifier Load

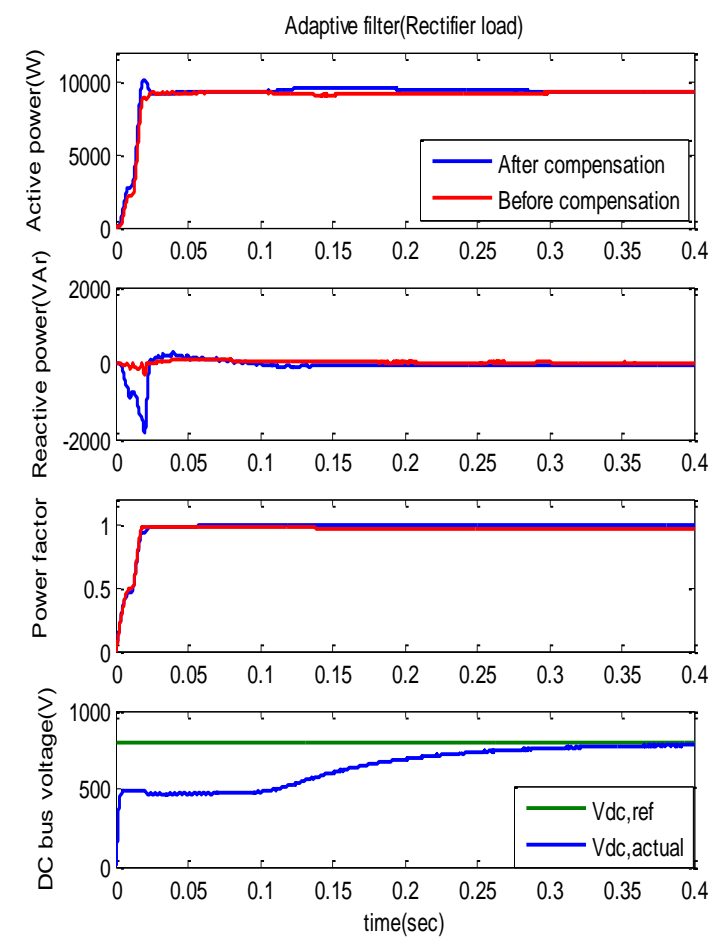

Fig. 5: Performance parameters of SAF for Rectifier Load
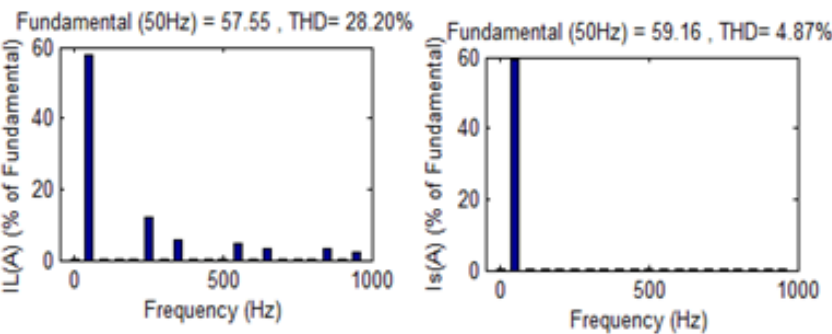

Fig. 6: FFT spectrum of load current, filter current and supply current for Rectifier Load 


\section{B. Simulation results for Electric Drives Load}

The Electric drives load current has low power factor and high reactive power due to increase in harmonics. The Shunt active filter is designed in such a way that the filter injects the high content of the harmonic current to the mains and the supply current is near to sinusoid as illustrated in Fig 7. The Active power and dc bus voltage of the filter reaches the steady state at $0.3 \mathrm{sec}$ which has more settling time compared to other two algorithms shown in Fig 8. The FFT spectrum shows the individual component of the load current, filter current and supply current. The 5th and 7th harmonic components are near to fundamental component thus the THD is above $100 \%$. The filter current injects the harmonic current and the supply current only carries the fundamental component demonstrated in Fig 9.
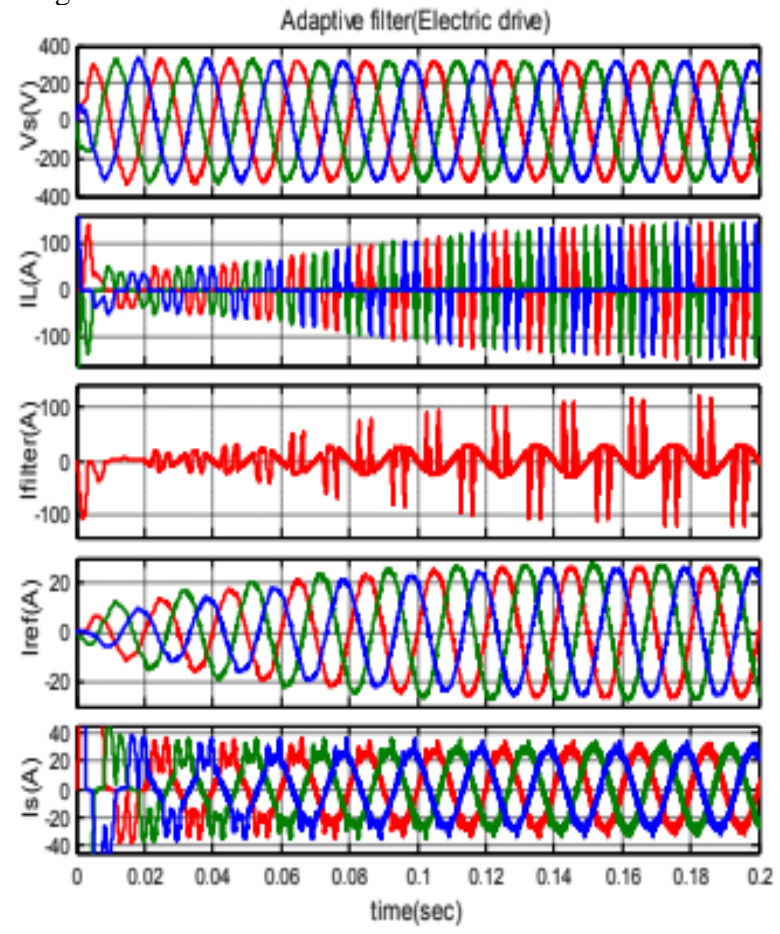

Fig. 7: Supply voltage, load current, filter current, reference current and supply current of Electric Drive Load
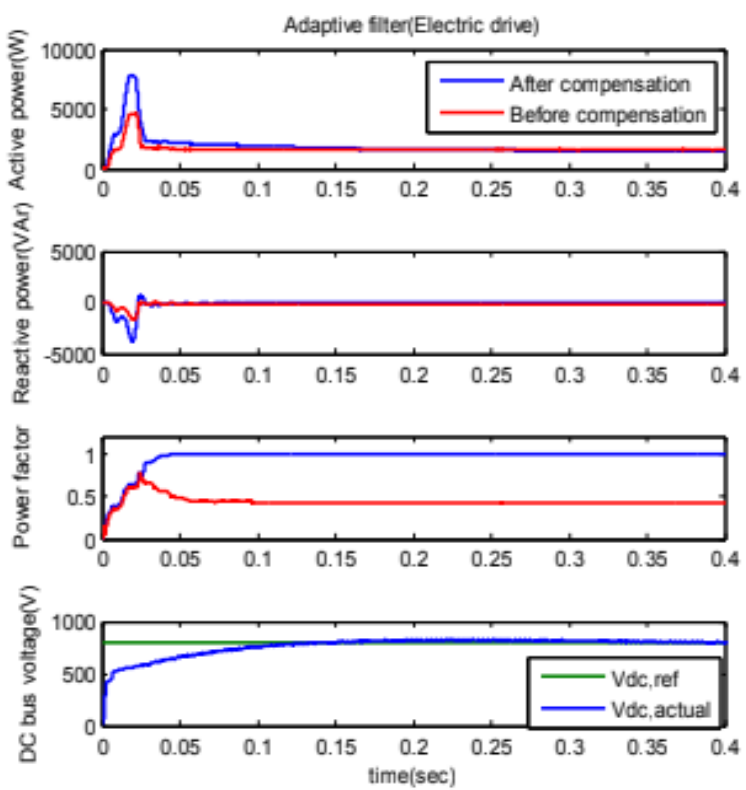

Fig. 8: Performance characteristics of SAF for Electric drive load
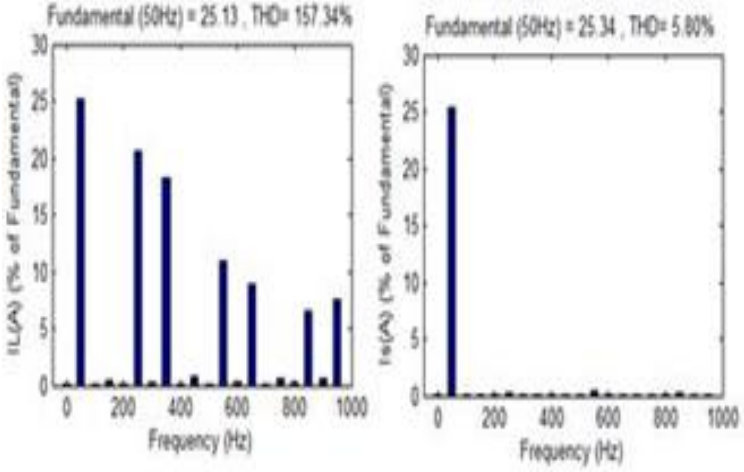

Fig. 9: FFT spectrum of load current, filter current and supply current for Electric Drive Load

\section{Simulation results for Induction Motor Load}

The fundamental reactive power is high and the power factor is low and the THD is low because the inductive load draws sinusoidal current from the mains depicted in Fig 10. As the THD is less than $8 \%$, harmonic compensation is not required for the inductive load but fundamental reactive current is more so reactive power compensation is required. The filter injects the reactive current at the fundamental frequency required for load as shown in Fig 11. Thus the supply current is reduced from $43.41 \mathrm{~A}$ to $34.97 \mathrm{~A}$ and the dc voltage of the active filter reaches constant at $0.32 \mathrm{sec}$ depicted in Fig 12.

Adaptive filter (inbuction modor)
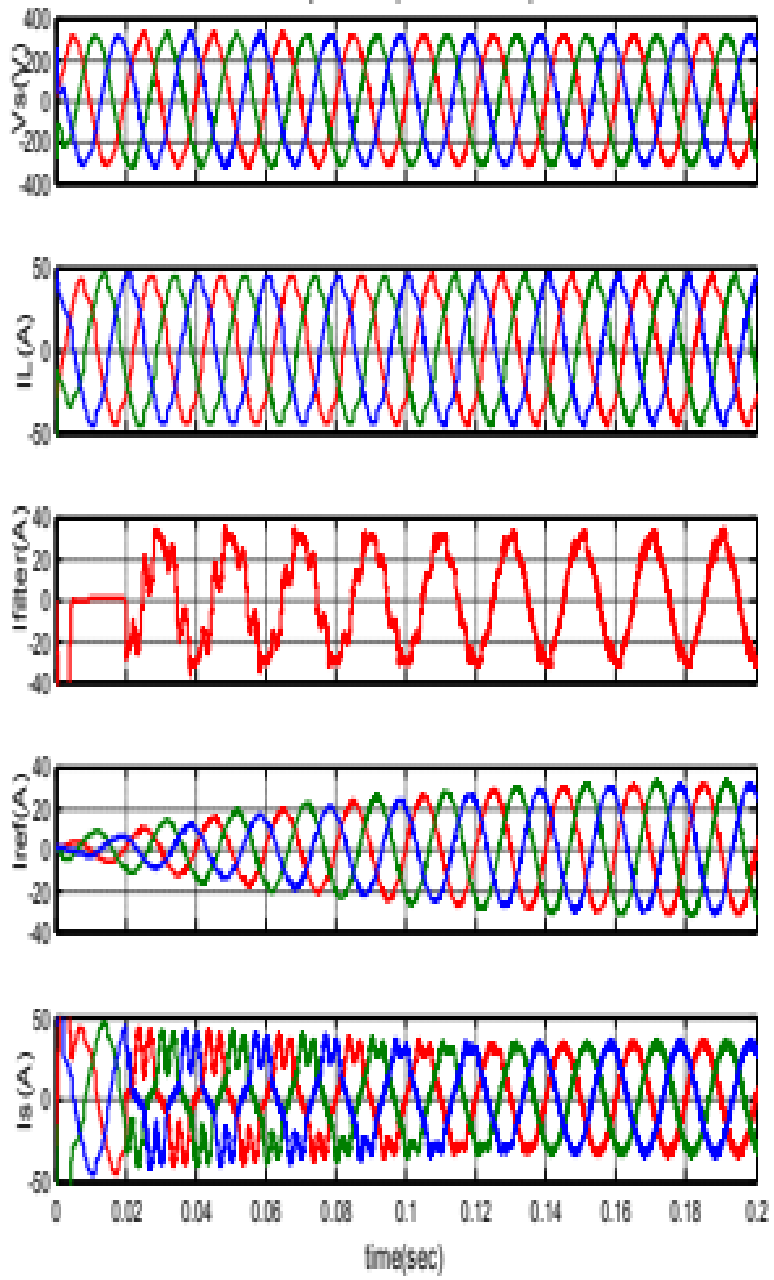

Fig. 10: Supply voltage, load current, filter current, reference current and supply current of Induction motor Load 

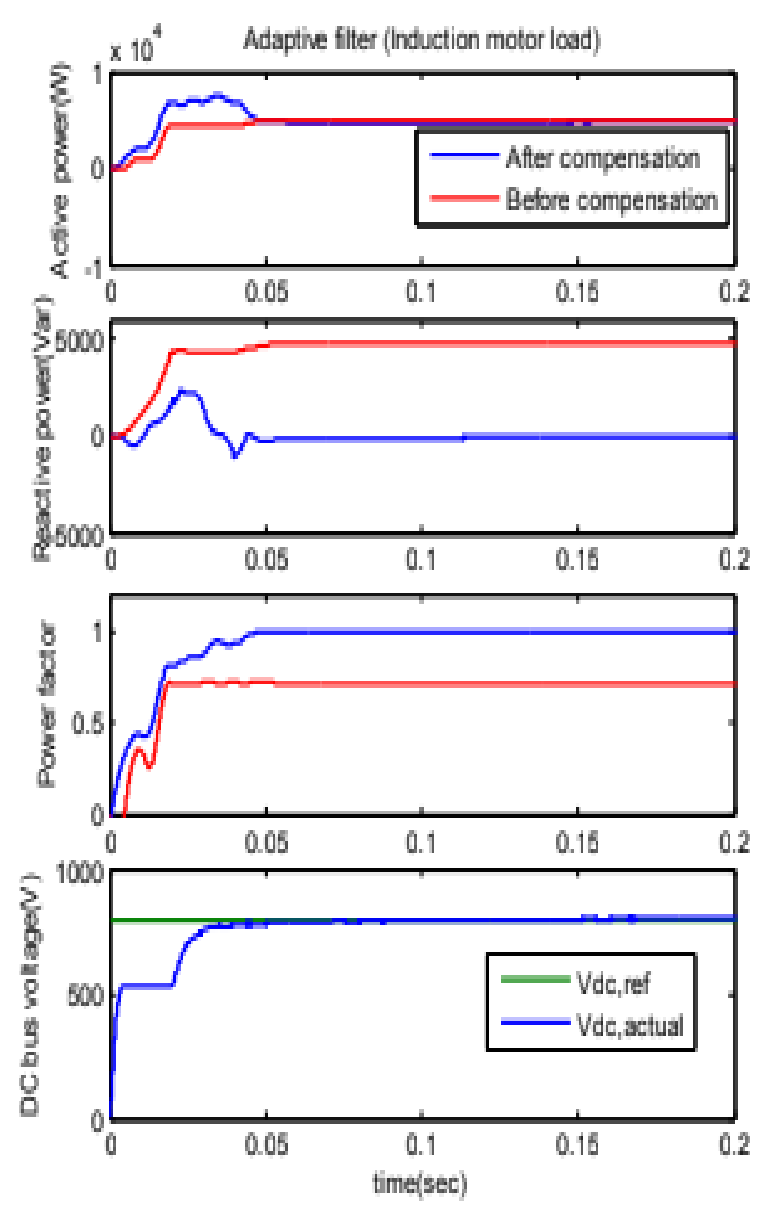

Fig. 11: Performance characteristics of SAF for Induction motor load
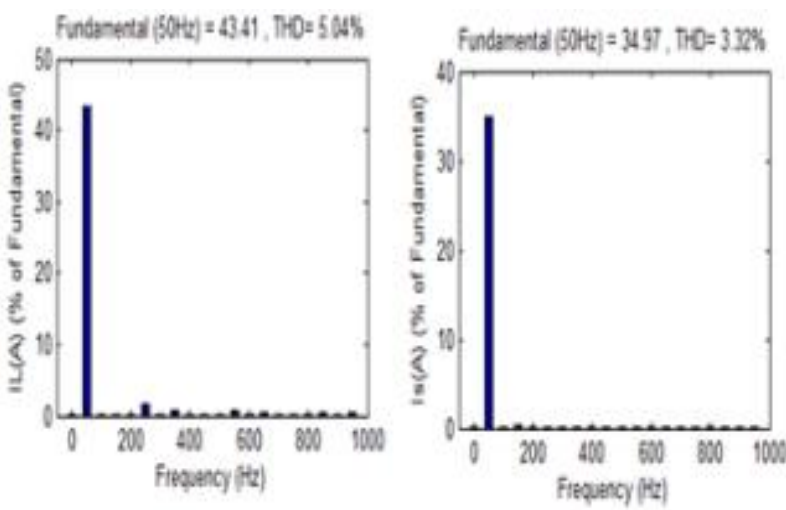

Fig. 12: FFT spectrum of load current and supply current for induction Motor Load

\section{Simulation results for Rectifier and Induction Motor Load}

The algorithm is tested in a distorted and lagging power factor of supply illustrated in Fig 13. The filter current injects the harmonic current as well as the reactive current to the mains. The high reactive power shown in Fig 14, reduces after compensation, and the power factor is increased from 0.74 to 0.9999 in supply unit. The dc bus voltage reaches the steady state at $0.28 \mathrm{sec}$.
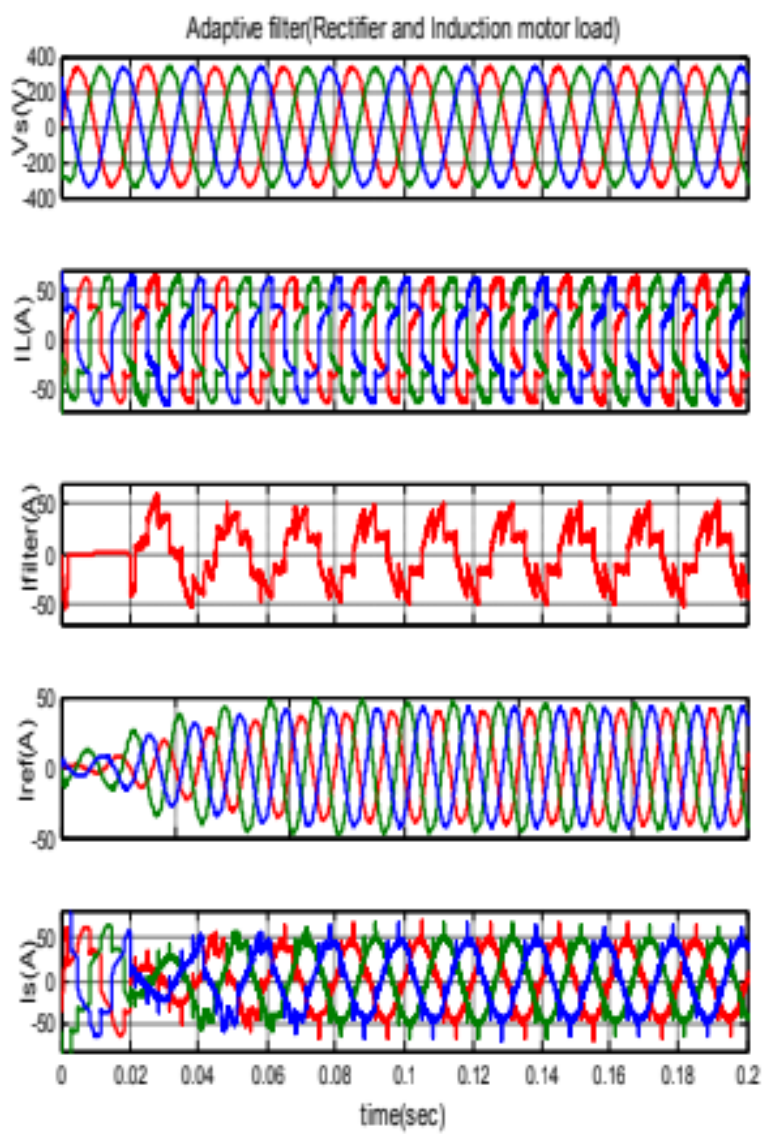

Fig. 13: Performance characteristics of SAF for Induction motor load
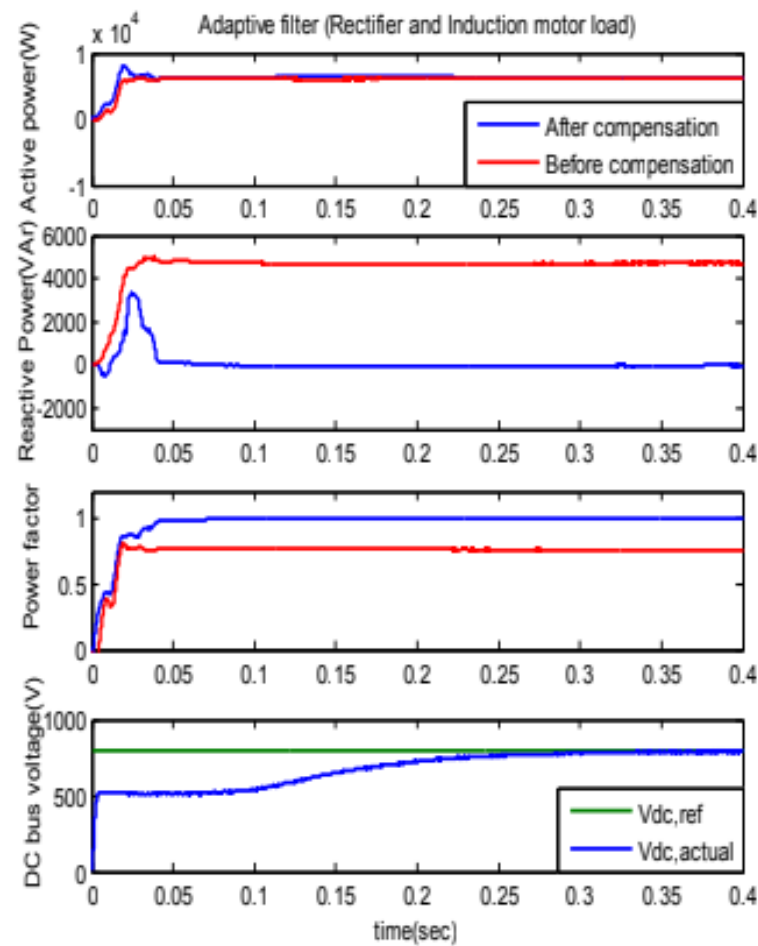

Fig. 14: Supply voltage, load current, filter current, reference current and supply current of Rectifier and Induction motor Load

The Table I and Table II illustrate the performance of the adaptive filter using LMS algorithm. The active power is maintained constant for all types of linear and non linear load. High reactive power due to high THD of the electric drive is reduced to a very low value for the compensated system. Thus the distortion factor is increased thereby increasing the true power factor and the apparent power is decreased from $7.38 \mathrm{kVA}$ to $4 \mathrm{kVA}$. For 3 -phase Induction motor load, after 
compensation the fundamental reactive power is reduced and the displacement power factor is increased which increases the true power factor of supply mains. For rectifier and Induction motor, the uncompensated current is high compared to compensated current which reduces the kVA from 8.88 to 6.74 . The Shunt Active Filter based on the control algorithm reduces the THD and increases the power factor.

Table 1: Comparison of the Performance Factor for Adaptive Filter using LMS Algorithm for Different Loads

\begin{tabular}{|c|c|c|c|c|c|c|c|c|c|c|}
\hline \multirow[t]{2}{*}{ Load } & \multicolumn{2}{|c|}{$\begin{array}{l}\text { Vs } \\
(\mathbf{V})\end{array}$} & \multicolumn{2}{|c|}{$\begin{array}{c}\text { Is } \\
\text { (A) }\end{array}$} & \multicolumn{2}{|c|}{$\begin{array}{c}\text { Ps } \\
(\mathbf{k W})\end{array}$} & \multicolumn{2}{|c|}{$\begin{array}{c}\text { Qs } \\
(\mathbf{k V A r})\end{array}$} & \multicolumn{2}{|c|}{$\begin{array}{c}\text { Ss } \\
(\mathbf{k V A})\end{array}$} \\
\hline & B.C & A.C & B.C & A.C & B.C & A.C & B.C & A.C & B.C & A.C \\
\hline Rectifier & 415 & 415 & 42.89 & 41.87 & 8.39 & 8.48 & 2.3 & 0.576 & 8.7 & 8.5 \\
\hline Electric drive & 415 & 415 & 33.12 & 17.95 & 3.76 & 3.98 & 6.35 & 0.348 & 7.38 & 4.0 \\
\hline Induction motor & 415 & 415 & 30.73 & 24.26 & 4.71 & 5.17 & 4.59 & 0.455 & 6.58 & 5.19 \\
\hline $\begin{array}{c}\text { Rectifier }+ \\
\text { Induction motor }\end{array}$ & 415 & 415 & 41.07 & 31.49 & 6.59 & 6.71 & 5.95 & 0.635 & 8.88 & 6.74 \\
\hline
\end{tabular}

Table 2: Comparison of Power Quality Factors for Adaptive Filter using LMS Algorithm for Different Loads

\begin{tabular}{|c|c|c|c|c|c|c|c|c|}
\hline \multirow{2}{*}{ Load } & \multicolumn{2}{|c|}{ Distortion factor } & \multicolumn{2}{|c|}{ Displacement factor } & \multicolumn{2}{|c|}{ True power factor } & \multicolumn{2}{c|}{ THD } \\
\cline { 2 - 9 } & $\mathbf{B . C}$ & $\mathbf{A . C}$ & $\mathbf{B . C}$ & $\mathbf{A . C}$ & $\mathbf{B . C}$ & A.C & B.C & A.C \\
\hline Rectifier & 0.964 & $\mathbf{0 . 9 9 7 7}$ & 0.9999 & $\mathbf{0 . 9 9 9 9}$ & 0.964 & $\mathbf{0 . 9 9 7 7}$ & 27.77 & $\mathbf{2 . 2 1}$ \\
\hline Electric drive & 0.5176 & $\mathbf{0 . 9 9 6 2}$ & 0.9848 & $\mathbf{0 . 9 9 9 9}$ & 0.5097 & $\mathbf{0 . 9 9 6 2}$ & 157.3 & $\mathbf{5 . 8}$ \\
\hline Induction motor & 0.9987 & $\mathbf{0 . 9 9 9 2}$ & 0.7169 & $\mathbf{0 . 9 9 8 3}$ & 0.7158 & $\mathbf{0 . 9 9 6 8}$ & 5.04 & $\mathbf{3 . 3 2}$ \\
\hline $\begin{array}{c}\text { Rectifier + } \\
\text { Induction motor }\end{array}$ & 0.9733 & $\mathbf{0 . 9 9 9 1}$ & 0.7729 & $\mathbf{0 . 9 9 7 9}$ & 0.7506 & $\mathbf{0 . 9 9 6 0}$ & 23.61 & $\mathbf{4 . 7 4}$ \\
\hline
\end{tabular}

\section{Conclusion}

Proposed algorithm mitigates the harmonics and compensate the reactive power for all type of load. The fundamental reactive power is compensated by the proposed algorithms compared to load reactive power. The proposed algorithms improve the power factor which is near to unity. Adaptive filter based current controller provides fast response compare to conventional algorithm as there is no need of Low Pass Filter to reduced ripple content of dq component.

\section{References}

[1] Rakhee Panigrahi, Bidyadhar Subudhi, Prafulla Chandra Panda,et.al.: "Model predictive-based shunt active power filter with a new reference current estimation strategy", IET Power Electron., 2015, 8, (2), pp. 221-233.

[2] Zhenfeng Xiao., Xiangtian Deng., Rongxiang Yuan., Pilong Guo., Qijuan Chen.,et.al.: "Shunt active power filter with enhanced dynamic performance using novel control strategy", IET Power Electron., 2014, 7,(12), pp. 3169-3181

[3] Leonardo B. Garcia Campanhol., Sérgio A. Oliveira da Silva., Alessandro Goedtel.,et.al.: "Application of shunt active power filter for harmonic reduction and reactive power compensation in three phase four-wire systems", IET Power Electron., 2014, 7, (11), pp. 2825-2836

[4] Zhang Fusheng, Geng Zhengxing, Yuan Wei. The algorithm of interpolating windowed FFT for harmonic analysis of electric power system",IEEE Trans on Power Delivery, Vol.16, No.2, pp.160-164, 2001

[5] R.Sriranjani and S.Jayalalitha, "Investigating the performance of various types of filter",WASJ, Vol 17, no.5, pp 643-650, 2012

[6] R. Sriranjani and S. Jayalalitha, "Harmonics and Reactive Power Compensation Using Shunt Hybrid Filter", Research Journal of Applied Sciences, Engineering and Technology, Vol. 5, Issue 1,pp.123-128, 2013

[7] R. Mahanty, "Indirect current controlled shunt active power filter for power quality improvement", International Journal of Electrical Power \& Energy Systems, Vol. 62, pp. 441-449, 2014

[8] S. Gautam, P. Yunqing, Y. Kafle, M. Kashif and S. Hasan, "Evaluation of Fundamental d-q Synchronous Reference Frame harmonic Detection Method for Single Phase Shunt Active Power Filter", International Journal of Power Electronics and Drive Systems, Vol. 4, No. 1, 2014
[9] S. Gautam, P. Yunqing, Y. Kafle, M. Kashif and S. Hasan, "Evaluation of Fundamental d-q Synchronous Reference Frame harmonic Detection Method for Single Phase Shunt Active Power Filter", International Journal of Power Electronics and Drive Systems, Vol. 4, No. 1, 2014

[10] R.Venkatesh, S.Dinesh kumar, R.Sriranjani and S.Jayalalitha, "Performance analysis of harmonic reduction by shunt active power filter using different control techniques", Journal of Theoretical and Applied Information Technology, VOL 63,1, PP 226 -232, 2014

[11] Seong-Chon Choi1, Sang-Hoon Song, Dong-Rak Kim, Min-Ho Sin and Chung-Yuen Won, "Shunt active power filter with enhanced dynamic performance using novel control strategy", IET Power Electronics, Vol.77, No.12, pp. 3169-3181, 2014

[12] Ricardo L'ucio de Araujo Ribeiro, Christian Cesar de Azevedo, Raphaell Maciel de Sousa, "A Robust Adaptive Control Strategy of Active Power Filters for Power-Factor Correction, Harmonic Compensation, and Balancing of Nonlinear Loads", IEEE Transactions on Power Electronics, Vol. 27, No. 2, pp. 718-730, 2012

[13] R.Sriranjani, S.Jayalalitha , "Power Factor Improvement and Harmonic Compensation using ANN Based Shunt Hybrid Filter for Active Load", ARPN Journal of Engineering and Applied Sciences, VOL. 10, NO. 12, pp 5132-5136,JULY 2015

[14] Dipti A. Tamboli and R. H. Chile, "Reference Signal Generation For Shunt Active Power Filter Using Adaptive Filtering Approach", International Conference on Industrial Instrumentation and Control, pp. 766-770, 2015

[15] M. Badoni, A. Singh and B. Singh, "Comparative Performance of Wiener Filter and Adaptive Least Mean Square based Control for Power Quality Improvement", IEEE Trans. Ind. Electron., pp. 1-1, 2016

[16] M. Badoni, A. Singh and B. Singh, "Adaptive Neuro Fuzzy Inference System Least Mean Square Based Control Algorithm for DSTATCOM", IEEE Transactions on Industrial Informatics, pp. 1-1, 2016

[17] Mohammed Qasim, Parag Kanjiya, and Vinod Khadkikar, "Optimal Current Harmonic Extractor Based on Unified ADALINEs for Shunt Active Power Filters", IEEE Transactions On Power Electronics, Vol. 29, No. 12, 2014

[18] R.Sriranjani.,S.Jayalalitha, "Design of Shunt Active Filter using Iterative Method to mitigate the Harmonics and Reactive Power", ARPN Journal of Engineering and Applied Sciences, Vol. 12, No. 24, pp. 7239-7249, 2017

[19] S.V.Manikanthan, Padmapriya.T, "RECENT TRENDS IN M2M COMMUNICATIONS IN 4G NETWORKS AND EVOLUTION TOWARDS 5G", International Journal of Pure and Applied Mathematics, Vol. 115, No. 8, pp: 623-630, 2017.

[20] S.V.Manikanthan and D.Sugandhi "Interference Alignment Techniques For Mimo Multicell Based On Relay Interference 
Broadcast Channel " International Journal of Emerging Technology in Computer Science \& Electronics (IJETCSE) ISSN: 0976-1353 Volume- 7 ,Issue 1 -MARCH 2014

[21] S.V. Manikanthan , T. Padmapriya "An enhanced distributed evolved node-b architecture in 5G tele-communications network" International Journal of Engineering \& Technology (UAE), Vol 7 Issues No (2.8) (2018) 248-254.March2018 